\title{
THE BIOLOGY OF LIMACINA RETROVERSA
}

\author{
By J. E. Morton \\ Department of Zoology, Queen Mary College, University of London
}

(Text-figs. I-5)

The Plymouth Fauna List contains records of two genera of pteropods, Limacina and Clione. Of the first, Limacina retroversa (Flem.) is by far the better-known species, apparently occurring regularly at Plymouth in large numbers in townettings from outside, and sometimes inside, the Sound. It breeds at Plymouth from June to August, and Lebour (1932) has given a detailed account of its breeding and larval stages and has discussed its role in the plankton. The second species of Limacina at Plymouth is lesueuri (d'Orbigny), which has been observed from time to time since 1906, when it was very common. The last record in the Fauna is off the Breakwater in 1920. Of the gymnosomatous pteropods, Clione limacina Phipps is the only species regularly occurring. Lebour (193I) has described the life history of this form, and mentions February to August as its months of greatest abundance. Its breeding season is June to August. Another gymnosome, tentatively referred to as Clionina longicauda, is reported by Russell (1936), and from the specimen department at Plymouth Laboratory the writer obtained some preserved specimens, not easily identifiable, of a Pneumodermopsis taken locally; its species is perhaps ciliata, recorded by Massy (1917) from the Irish Coast.

In spite of its abundance and wide distribution, Limacina has not been carefully studied in the living condition. In Meisenheimer's long account (I905) of pteropod morphology, the functional aspect is rather understressed. Nor did Yonge (1926), in his account of feeding mechanisms in thecosomatous pteropods, deal with Limacina. A knowledge of this genus would, however, undoubtedly shed much light on the study of the larger and more specialized thecasomes. Hsiao (1939) has already worked on the sexual succession and life history of populations of $L$. retroversa; the present writer has completed an account of the genital system and reproduction of L. bulimoides from the South Atlantic. During the summer of 1952, when abundant and active material of L. retroversa was available at Plymouth, an opportunity was taken to examine its movements, mode of feeding, and the structure and action of the digestive system. From similar living material of Clione limacina, it is later intended to give an account of the structure and reproduction of this pteropod.

I am indebted to the Director and Staff of the Plymouth Laboratory of the Marine Biological Association for their kindness during my tenure of the 
University of London table; and I have especially to thank Dr D. Atkins for first obtaining samples of living material for me, and for drawing my attention to its times of abundance at International Hydrographic Station E I.

\section{MOVEMENTS}

Limacina swims with the aperture of the shell upwards and the surface of the foot widely exposed above. Its movements in a laboratory vessel consist of repeated upward migrations to the surface, describing a broadly spiral course, followed by a more rapid and direct descent during which the wings are out of action. In upward swimming the rhythmically flapping wings constitute a tractellum producing an eddy behind which the animal moves. The effective stroke appears to come about by the contraction of the sheet of muscle fibres running through the base of the ventral side of each wing, underlying the ciliated field, to be referred to below. At the resting stage, the dorsal muscle sheet of the wings would appear to contract and the thicker bases are reflected backwards against the shell to show their under-surfaces which are also ciliated. The expanded tips of the wings are transparent and non-muscular. They are held freely relaxed until a contraction of the dorsal muscle flicks the bases forward again. During descent the wings offer no resistance to the water and are held erect and close together above the animal, forming-when viewed from above-two planes at an oblique angle. The weight of the compact shell and body quickly carried the animal downwards. Fig. I illustrates the successive positions of the wings during swimming. From references in the literature to other Thecosomata (see, for example, Stubbings, 1937), it seems likely that the principal movements of these pteropods are in a vertical direction, with the surface of the foot widely exposed for feeding. In L. bulimoides there is evidence that this species performs regular diurnal depth migrations (Morton, 1954).

\section{FOod COLLECTING}

Limacina is entirely a ciliary feeder. It apparently lives chiefly upon dinoflagellates and suitably shaped diatoms. When the Thecosomata became pelagic it is probable they had already lost the ctenidium which was used to produce food-collecting currents in ciliary-feeding prosobranchs. They rely to a much greater extent on the ciliated surfaces of the foot. Yonge (1926), in his account of feeding in the Cavoliniidae and Cymbuliidae, maintains that feeding is carried out entirely by the lobes of the foot, and the cilia at the bases of the wings. As we shall later discuss, it is clear that these families are a good deal more advanced in structure than the spiral-shelled Limacinidae, where it would appear that, in spite of the loss of the ctenidium, the mantle cavity is still the most important feature of the feeding apparatus.

We may first look at some external structures of L. retroversa (Fig. 2) of which the most prominent are the foot and the wings. The foot consists of 


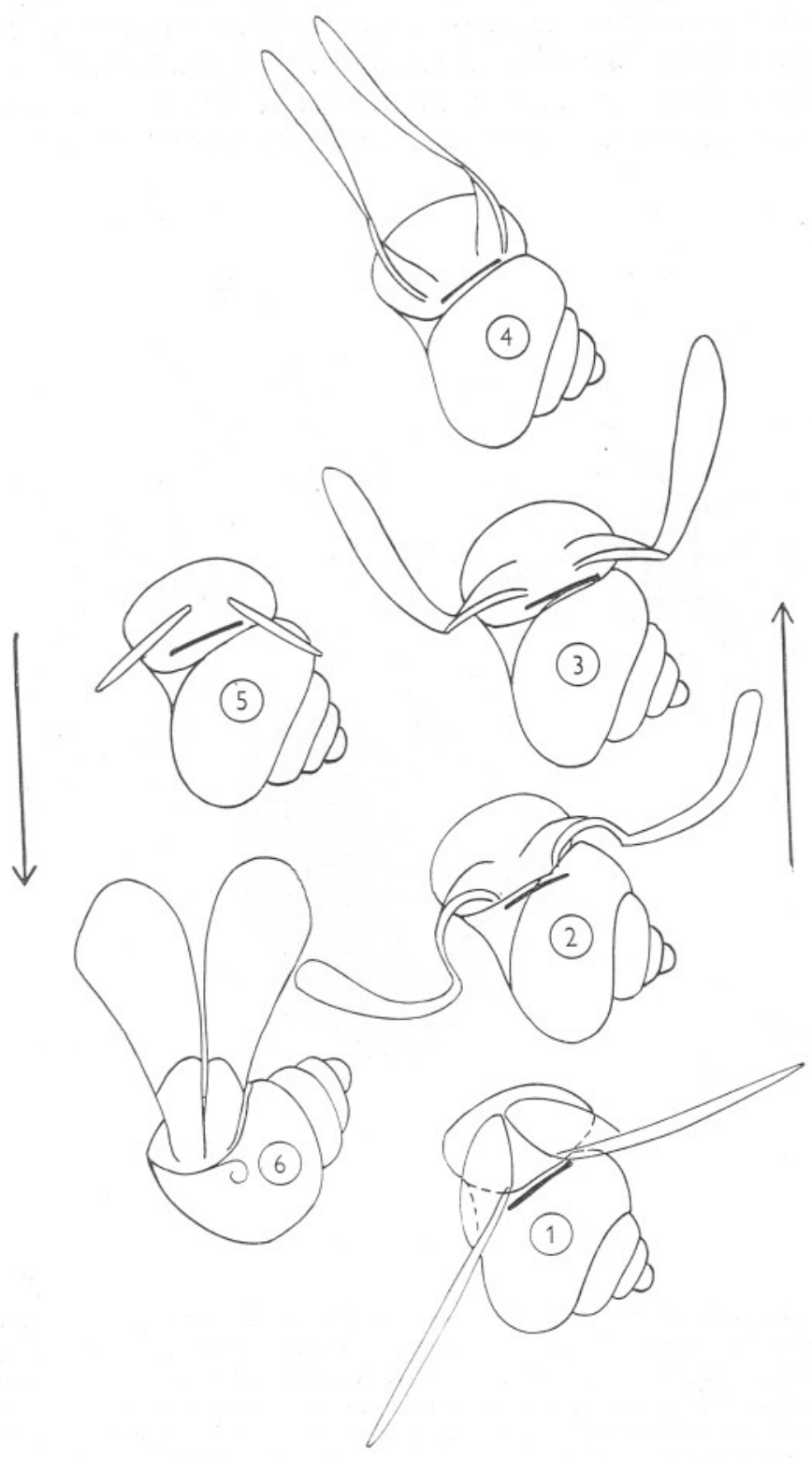

Fig. I. L. retroversa. Outline drawings showing successive positions of the wings in swimming upwards ( $(-4)$, and in descending (5). 6 shows the wings held motionless and vertical, in a different view from 5 . 
a flat median lobe $(M L)$ flanked by two narrower lateral lobes (LAT L). The median lobe is broadly triangular or heart-shaped, widest behind and carrying upon its back surface the transparent, chitinous operculum, golden yellow in colour. This is almost always retained in limacinids though, as Lebour (1932) points out, it may often drop off in older specimens of $L$. retroversa. The flat

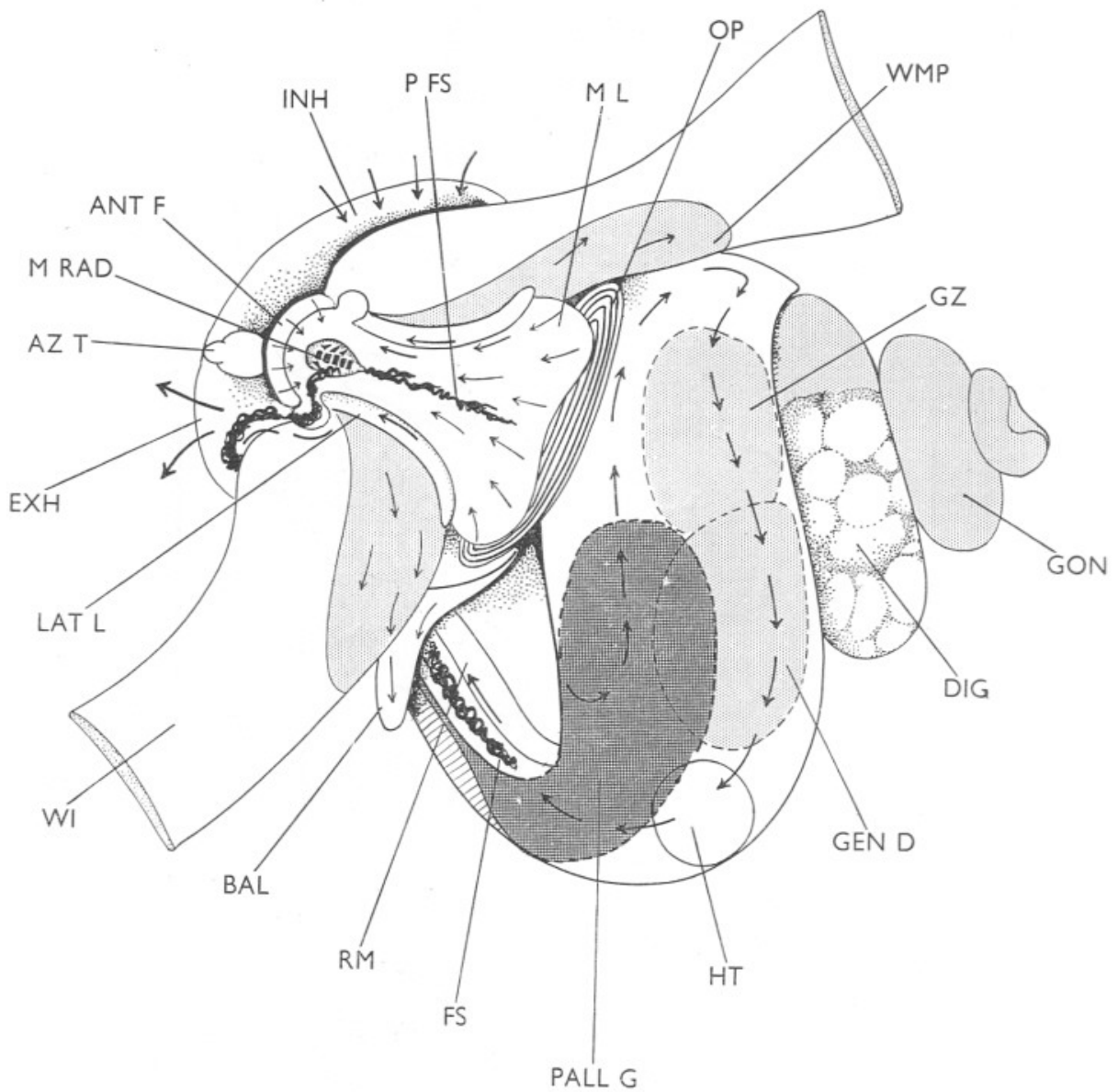

Fig. 2. L. retroversa, ventral view. Diagram showing the ciliary currents employed in food collecting. The surface of the foot and the ciliated portions of the wings are fully expanded, and the distal parts of the wings are omitted. The contents of the pallial cavity are shown as if transparent, the pallial mucus gland, the genital ducts and the stomach being represented by stippled areas. ANT F, anterior horseshoe-shaped fold; $\mathrm{AZ} \mathrm{T}$, azygous tentacle; BAL, balancer; DIG, digestive gland; EXH, exhalant side of pallial cavity; FS, food string within the pallial cavity; GON, gonad; GEN D, genital duct; GZ, gizzard; HT, position of the heart; INH, inhalant side of the pallial cavity; LAT L, lateral lobe of the foot; $M L$, median lobe of the foot; $M$ RAD, mouth, with the radula; OP, operculum; P FS, food strings formed on the median lobe of the foot; PALL G, pallial mucous gland; RM, rectum; WI, wing; WMP, ciliated 'Wimperfeld' at base of wing. 
surface of the median lobe represents the sole and is finely and uniformly ciliated, and covered with unicellular mucous glands. In front it narrows rapidly, and channels forward towards the mouth between the two lateral lobes which form straight or crescentic folds, bounding the sole on either side from the bases of the wings. These folds are dark brown or blackish in colour, and beneath them and along their edges are tracts of dense forward-beating cilia. These lead into a shallow funnel-shaped depression, enclosing the mouth, and bounded in front by a small, horseshoe-shaped fold (ANT F), lighter brown in colour. Outside the lateral lobes of the foot spring the paired swimming wings, diverging at right angles, one at either side. They expand slightly towards the free tips, which are thin and membranous and somewhat squarish. Each wing has two areas, a rather smaller triangular area at the base, widest posteriorly, and bearing cilia (referred to as the 'Wimperfeld' by Meisenheimer), and the longer free flaps which are colourless and translucent. The ciliated areas are thicker and firmer, and the contraction of their dorsal and ventral muscle sheets results in the movements causing locomotion. In front of the horseshoe-shaped fold bounding the mouth, the head bears a single azygous tentacle (AZ T) with a short terminal papilla inserted in a cylindrical base. Its unpaired condition is a peculiar and unexplained feature, which seems to be common to limacinids in general (Pelseneer, I888).

The coiling of the visceral mass is sinistral so that the inhalant and exhalant openings of the mantle cavity are reversed from the position usual in gastropods. The pallial aperture is wide and unconstricted, but the chief point of entry of the water current is on the left side near to the posterior corner of the pallial opening. Here the rim of the mantle is encircled with dense cilia beating inwards; their action is so strong that the particles from the surrounding water from a distance of 5-10 $\mathrm{mm}$. are rapidly cleared and drawn into the pallial cavity. Along the whole of the inhalant side, the inner surface of the mantle is clad with cilia. A short way behind the aperture it becomes glandular, with the appearance of a thick, broad shield of mucus-producing epithelium, which extends around the longer or concave side of the pallial cavity and reaches back to the pericardium on the right side. This is the 'shield' or pallial gland, mentioned by Pelseneer (I888) and the 'manteldruse' of Meisenheimer, and in its structure and histology it forms a very constant feature of all known Thecosomata. In position it has the same relations as the hypobranchial gland of prosobranchs, though in histology there seems to be no real similarity. Meisenheimer (1905) provides a simple figure of the 'manteldruse', and we may illustrate it again here for Limacina (Fig. 3, right side). The glandular cells are of uniform height $(45 \mu)$ and width $(5 \mu)$, and the superficial layer of the epithelium, to about one-fourth its depth, contains a row of ovoid mucous droplets, ready for secretion. The remaining cytoplasm after Bouin's fixation tends to break up into a number of vertical strands of darker staining secretion (brown in azan) while the large, binucleolate nuclei lie in a single 
row at the base of the epithelium. Ciliated cells are smaller and less frequent, about one to each pair of glandular cells. They appear as tiny wedges with dark nuclei, inserted between the tips of the glandular cells, but they have evidently a narrow drawn-out connexion with the basement membrane and seem to remain intact during secretion.
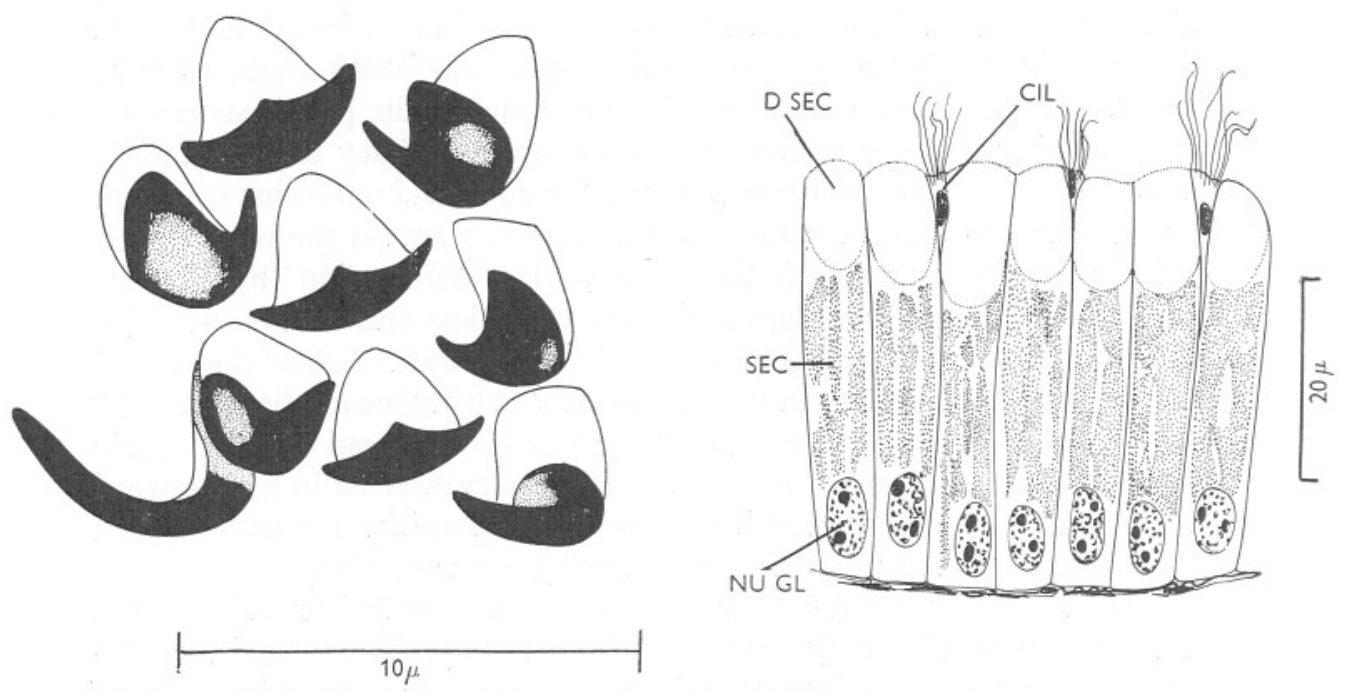

Fig. 3. L. retroversa. Left side. Three rows of radular teeth. A lateral mounted flat is shown in the lower row, left side. Right side. Epithelial cells of the pallial mucous gland. (Bouin's fluid, Heidenhain's azan). CIL, ciliated cell; D SEC, distal droplet of secretory material; NU GL, nucleus of gland cell; SEC, darker staining secretory material in the middle part of the cell.

The function of the pallial gland in Limacina is to provide mucus for compaction of the particles entering the inhalant side of the pallial cavity, and to carry forward a coherent string of collected particles along the right side of the cavity. Fig. 2 shows the course of the ciliary currents carrying particles into the pallial cavity. There is a strong inward stream on the left side to the tapered upper end of the cavity, with a sharp reversal at the top, and the return of collected material along the pallial glandular strip at the right side. This part of the pallial cavity in Limacina, extending far back alongside the stomach and anterior part of the digestive gland, calls to mind in a more elementary form the more elaborate pallial caecum of Actaeon (see Fretter, in press) and Scaphander, with inward and outward ciliary currents. Limacina itself would appear to require little help from ciliary currents in this region: the whole circulation is probably brought about chiefly by the action of the inhalant cilia lying farther forward. Only the lightest of particles seem to make the complete circuit of the pallial cavity. Coarser material, of the size of diatom 
frustules, constantly appears to drop out of the stream on to the pallial mucous gland, and to become bound up into the string that constantly moves forward on the right side. This string is carried by cilia along the surface of the glandular sheet (FS) and issues from the mantle cavity on the right side at the anteriormost part of the aperture. Its contents are regularly ingested. They make their way to the funnel containing the mouth, across a tiny, saddleshaped depression, between the right lateral lobe of the foot and the horseshoe lobe. There is a similar depression on the left side, which was however never seen to be crossed by a food string. At the bottom of the funnel the narrow radular ribbon is thrust from the mouth, and the tiny chitinous teeth take hold of the string and detach a small bolus, which is swallowed into the buccal mass by rapid thrusts of the odontophore. Around the mantle margin as a whole there is a region of strong ciliation. Here, to a smaller extent, particles may be carried directly across the rim and into the mantle cavity. Some particles too may alight upon the horseshoe-shaped anterior lip, where they are caught up by cilia and travel direct to the mouth. Others again, being rejected, find their way on to the ciliary tracts of the under surfaces of the wings and are carried outwards and cast off. These may include larger and looser particles breaking away from the pallial string.

In addition to the collection of food particles in the pallial cavity, a significant part is played also by the foot in L. retroversa. This, however, would appear to be much less important than is the case in the Cavoliniidae and Cymbuliidae. Particles alighting on the free surface of the median lobe receive a covering of mucus and are carried forward by cilia in small strings (P FS) directly to the mouth, along the channel between the lateral lobes. Especially strongly ciliated are the brown-pigmented lateral lobes. These have long, close-set cilia keeping up a swift current carrying further particles, embedded in mucus, to the mouth.

On the ciliated bases or 'Wimperfeld' of the wings, the food-collecting action seems much less important. The cilia are shorter than on the lateral lobes of the foot, the direction of current less decisive. So far as could be determined the cilia of the 'Wimperfeld' beat outwards, away from the foot, and their action on particles alighting on the wings is probably rejectory. The flapping of the wings in swimming also serves to dislodge particles from both the upper and lower surfaces; and it would not appear that particles collected on the wings could be easily transferred across the side lobes of the foot in the direction of the oral funnel. The dorsal surfaces of the bases of the wings, which lie closer against the shell, also possess rejectory currents carrying particles away from the mid-line.

A rejectory action seems also to be carried out by the short triangular lobe or 'balancer' (BAL), which Pelseneer has noticed as an outgrowth of the pallial skirt on the right side. Rather strong ciliary currents here proceed from the edge of the mantle, along the lobe to its tip. 


\section{DigESTIVE SYSTEM}

The regions of the gut were described briefly by Pelseneer and Meisenheimer. There is a tiny buccal bulb with an odontophore bearing the radula and a small chitinous jaw. The radula is figured for L. retroversa (Fig. 3, left side). Tesch has already illustrated it (1946) for the larger helicoides, and the small differences apparent are due chiefly to variations in the inclination of the teeth in the preparations obtained. As stated by Pelseneer (I888) and by Tesch, Limacina possesses three teeth in each row, a single-cusped median, flanked by two laterals. The oesophagus leads backwards as a fine tube, lined with short cilia, beating rapidly backwards along its whole length. The salivary glands are minute, secreting mucus through the ciliated roof of the buccal bulb. The narrow part of the oesophagus widens greatly at its posterior end into a conical gizzard, broadest behind, and strongly invested with circular muscle. This organ differs somewhat in shape from that of Cymbulia, described by Howells (1936), but is so essentially similar, both in its histology and the arrangement of its teeth, as to need little further description. Each tooth forms a stout thickening of the cuticular lining of the gizzard, terminating in a backwardly curved claw. Four teeth fit very closely together, forming a strong mill filling the whole of the central part of the gizzard. A fifth tooth lies posteriorly, near the threshold where the stomach proper begins; it is smaller and less elevated, forming a flat, thickened sheet of cuticle.

The gizzard, as in all the tectibranchs, is oesophageal, and the stomach, properly so-called, opens widely from it behind. It forms a compact, thinwalled bag, finely ciliated throughout, and serves essentially as an annexe to the single digestive diverticulum. The stomach is illustrated in transverse section in Fig. 5, upper, from which it will be seen to have two exits, the digestive diverticulum and the narrower intestine. In addition, there is a small, more strongly ciliated pocket opening into the stomach opposite the digestive diverticulum. This corresponds, from its structural relations and the nature of its epithelium, to the style caecum which has been found to survive in each of the thecosomatous pteropods investigated. In Cymbulia it is a longer, blunt-tipped tube; in Limacina it is little more than a rounded pocket only $25 \mu$ in greatest diameter. The epithelium is extremely low, cuboidal or even squamous, $\mathrm{I}-2 \mu$ in height, never glandular, and the cilia are long and slender, about twice the length of the cells and always difficult to activate in living material. The contents of the sac, after fixation in Bouin's, consist of a reticulum of mucus, rather denser than in the rest of the stomach. There was never a rotating rod visible in living animals; but from its characteristic ciliated lining, and from the presence in Cymbulia of a transparent 'style', it is hard to deny this sac, vestigial though it is, the character of a style caecum. Its function must be little if any at all; the mode of action of the stomach and gizzard is one in which the gentle rotation of a style can play no part. The 


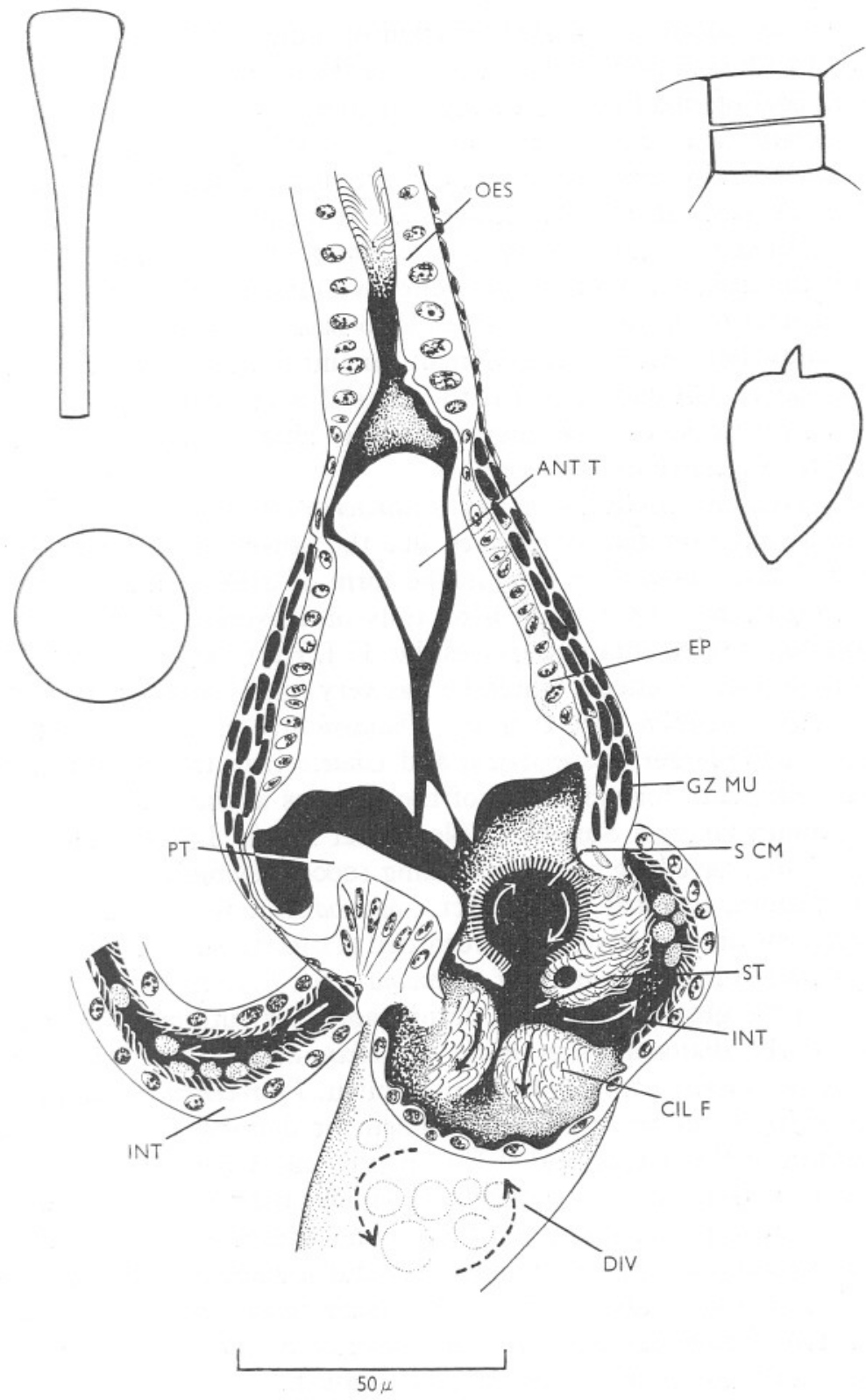

Fig. 4. L. retroversa. The gizzard and stomach represented in longitudinal section, chiefly as seen by transparency in the living animal, with structural details supplied from histological observations. The arrows show the directions of the principal ciliary currents. To the same scale are drawn outlines of three species of diatoms and one dinoflagellate, presumed to form part of the food supply of L. retroversa at Plymouth. (Left upper, Asterionella japonica; left lower, Skeletonema mediterraneum; right upper, Chaetoceros constrictus; right lower, Prorocentrum micans.) ANT T, one of the four anterior teeth of the gizzard; CIL F, ciliated fold at the entrance to the digestive diverticulum; DIV, digestive diverticulum; EP, epithelium underlying a gizzard tooth; GZ MU, circular muscles of the gizzard; INT, intestine; OES, oesophagus; PT, posterior tooth of gizzard; s CM, style caecum; ST, cavity of stomach. 
digestive diverticulum is bounded by a pair of rounded folds, closely approximated and with cilia beating outwards from the stomach. Into the intestine, a uniform coat of cilia beats in an anal direction.

The gizzard is a structure perhaps unexpected in a ciliary and mucous feeder, but when looked at in action in the living animal, its presence is less difficult to explain. Its circular muscles are strongly contractile, and its four anterior teeth closely interlock across the lumen. They open apart when the gizzard is distended, to form a most effective mill, through which particles with a diameter of up to $40-50 \mu$ are able to pass. Expansion of the gizzard serves to draw between the teeth a small amount of mucus-bound food from the oesophagus. On contraction hard material is crushed and the contents released in the form of tiny fragments easily able to be received into the mouth of the digestive diverticulum.

Although diatoms could not be fed to Limacina retroversa in the laboratory, it is a fair assumption that this species, like the other members of the genus investigated, takes most of its food in the form of diatoms and other phytoplankton organisms, many with hard tests or frustules. For L. helicoides, one of the larger sized antarctic species, Dr T. J. Hart has made the following analysis of stomach contents which he has very kindly allowed me to quote: Fragilariopsis antarctica (size c. $30 \mu$ ), Thalassiosira (c. $35 \mu$ ), together with fragments of the larger Coscinodiscus and Chaetoceros, the latter being very large and dominant, forming $75 \%$ of the diatoms at the station referred to (St. 500, South Georgia Survey, 21 November 1930). Larger individuals of Chaetoceros spp. have long bristles, reaching $1000 \mu$ in length, and it is obvious that this diatom, together with intact Coscinodiscus, was being rejected as unwieldy. Few dinoflagellates were recorded at this station, and no specimens are mentioned from the stomach of Limacina. For L. retroversa at Plymouth, the figure of the gizzard (Fig. 4) is accompanied by outlines to similar scale of three of the diatoms, Asterionella japonica, Skeletonema mediterraneum and Chaetoceros constrictus, and one peridinian, Prorocentrum micans, stated by Lebour (1918) to be especially abundant or dominant in the plankton at the mouth of the Sound, and at E I, in July and August. The oesophagus of retroversa, with its five or six longitudinal folds can be widely distended with the passage of larger particles, and there is no reason to believe any of the above phytoplankton organisms would be found unmanageable. In addition, no doubt, Limacina is able to exploit the large resources of nanoplankton, including naked flagellates, though the presence of these quickly digestible organisms in the gut is much less easy to establish.

The passage of carmine particles through the alimentary canal is relatively swift. Material administered in the laboratory and ingested from the pallial food string is received from the stomach into the intestine in $30 \mathrm{~min}$. after ingestion. Carmine is never admitted to the digestive diverticulum, and having once reached the intestine it is discharged from the anus about $2 \mathrm{~min}$. 
later, being impelled through the intestine in a loose faecal rope, with the help of both cilia and peristalsis.

The muscular action of the gizzard in Limacina provides also a pumping action. There is a constant ebb and flow between the stomach and the digestive diverticulum, of a watery mucoid substance, containing suspended yellowish green droplets as well as black and dark brown particles extruded from the excretory cells of the digestive gland. This material is thoroughly circulated within the stomach, while the intestine is held closed, either by the approximation of its walls, or the presence of more solid faecal particles. At intervals, most of the particles from the digestive gland are forcibly ejected as a compact mass into the intestine. Fragments of diatom cases seldom appear to enter the diverticulum, but find their way straight through to the intestine. There is little muscular contraction by the wall of the stomach proper-most of the compression of the stomach is supplied from the gizzard. Neither are there any evident gland cells in any part of the oesophagus, or stomach. Mucus is provided from the mantle cavity and foot, and in smaller part probably from the salivary glands.

The digestive gland is a long, wide tube forming most of the visceral mass, anteriorly to the gonad. It is dark greenish yellow in colour, packed with particles which appear strongly refractile in the intact animal. The lining of the gland has no cilia-there is merely a tapered flange of ciliated cells from the stomach, running backward into the diverticulum, and soon giving way to digestive tissue.

The structure of the epithelium (Fig. 5, lower) is notable for its strong resemblance to that of Cymbulia as described by Howells (1936). The lumen is pocketed into small shallow lobules ( $50 \mu$ across), set close together by their basement membranes, and lined with cells of three types. The most numerous are the digestive cells, which, at the phase of activity at which they were examined, tend to be squarish or broader than long. They contain two sorts of vacuoles, the basal ones filled with finely granular material staining blue in azan, the more superficial ones on the whole larger, and colourless. The digestive cell at its intact stage has the finely striated border referred to by the present writer (in the press) in the Ellobiidae, and there is throughout a general resemblance between the digestive cells in primitive pulmonates and opisthobranchs. No stages in the formation of 'fragmentation phagocytes' were observed in material of Limacina, and from the stage of activity at which the gland was sectioned these are probably not to be expected. The remaining two types of cell are to be regarded as excretory, and both have already been observed by Howells in Cymbulia. The first have large rounded nuclei, with prominent nucleoli and chromatin strands and their cytoplasm stains uniformly dark brown with azan or black with Heidenhain's haematoxylin. The second are rather smaller, very broad-based and triangular; their cytoplasm is filled with small distinct spherules staining deeply black with haematoxylin. 


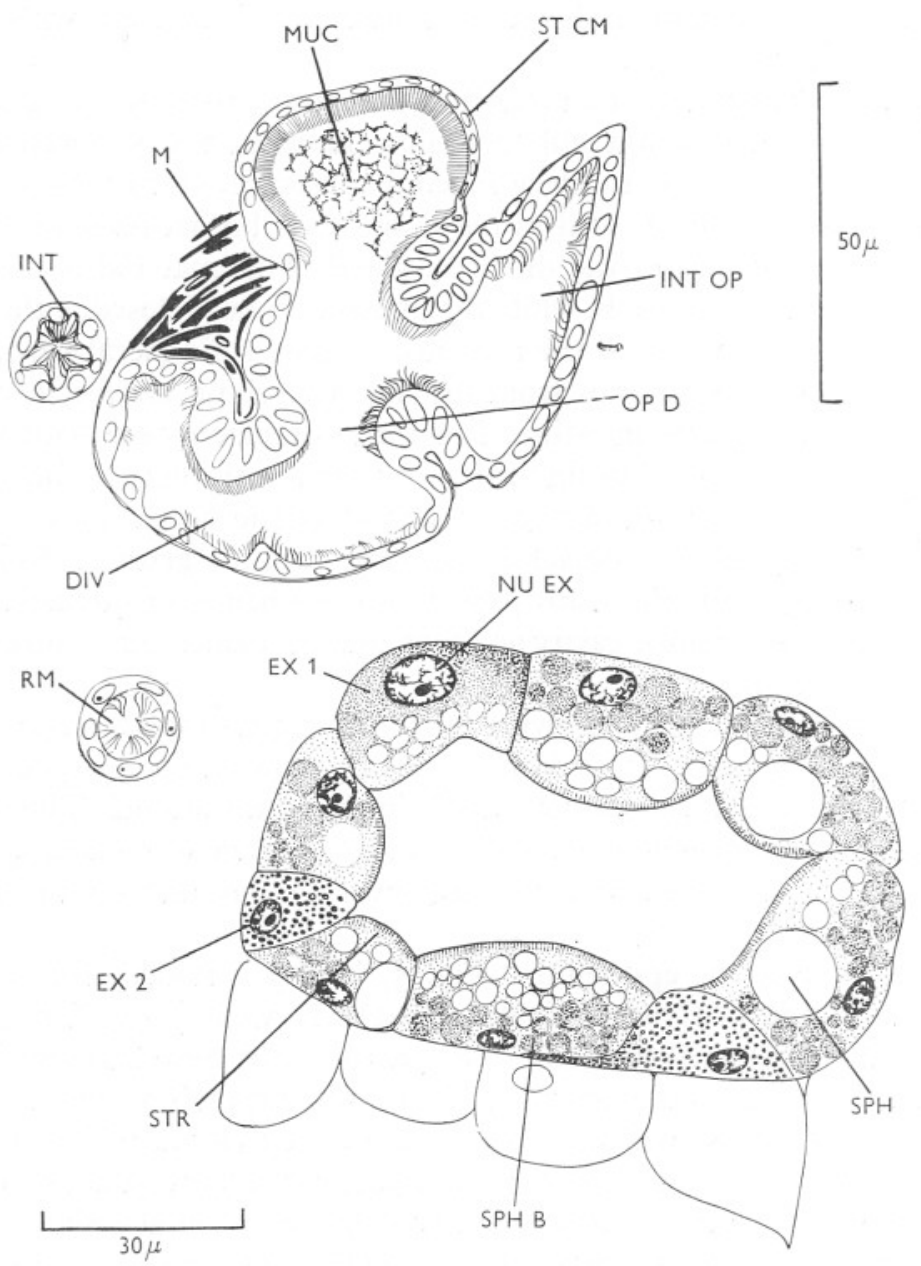

Fig. 5. L. retroversa. Upper. Transverse section passing through the stomach, intestine and rectum. DIV, digestive diverticulum; INT, intestine; INT OP, opening of the intestine from the stomach; $M$, hindmost part of gizzard muscles; MUC, mucous contents of style caecum; OP D, opening of digestive diverticulum from the stomach; RM, rectum; ST CM, style caecum. Lower. Section of a single lobule of the digestive gland. (Bouin's fluid; Heidenhain's azan.) EX I, EX 2, two types of excretory cells; NU EX, nucleus of excretory cell; SPH, clear spherule of digestive cell; SPH B, blue staining vacuole of digestive cell; STR, striated border of digestive cell.

\section{Discussion}

Pelseneer first provided a reliable anatomical account of the pteropods, and he settled the distinctness of the two groups Thecosomata and Gymnosomata. The collective name 'pteropods' survives now only as a convenient term of common 
reference for pelagic tectibranchs. Thus the more recent classification adopted by Thiele (I93I) and by Hoffmann (I939), reverting to a single order Pteropoda as a major division of the Opisthobranchiata, must be regarded as an altogether retrograde step. The Thecosomata and Gymnosomata are unlike in almost all features with the single exception of their habit of swimming. They are almost certainly separately derived from bottom-dwelling groups of tectibranchs. The Thecosomata are entirely ciliary feeding; the Gymnosomata are active carnivores, very often feeding on small thecasomes, and in the majority of their characters they are very much more specialized. It is hoped in a forthcoming paper to give a better account of the anatomy and reproductive history of the British gymnosome Clione limacina.

Our knowledge of small thecosomatous pteropods is rather better than for the Gymnosomata. Here we have the advantage of an animal with a hard shell, or a pseudoconcha, which suffers much less damage in collecting and survives longer in the laboratory. Of this group we now have an adequate knowledge of the feeding mechanism, digestive system, sexual succession and reproductive organs; and in oceanographic literature Limacina is well known for its ecological importance as a grazer on phytoplankton. All our evidence confirms Pelseneer's derivation of these animals from bullomorph tectibranchs; an instructive parallel is provided by Acera which has developed an ability to swim by the enlargement of its parapodial lobes, though this animal has probably little to do with the actual phylogeny of the pteropods. Limacina, which is still shelled, spirally coiled and operculate, is in all ways an excellent form for an understanding of the transition to pelagic pteropoda.

Pteropods have been previously looked at as living animals chiefly by Yonge (I926). He did not, however, examine Limacina, and in this generalized form there are now several differences to report from the Cavoliniidae and Cymbuliidae. Paradoxically, so small a creature as Limacina is much easier to examine intact and living than the larger pteropods; its mode of feeding and the action of the gut are readily observed through the transparent shell, and it remains happily alive in sea water in the laboratory for many days.

It is admitted by all that the three families of Thecosomata, the Limacinidae, Cavoliniidae and Cymbuliidae, stand in that order of specialization; and within the Cymbuliidae it is probable that Gleba, as suggested by Yonge, is the most advanced genus. In food-collecting the greatest point of difference is the absence in the Cavoliniidae and Cymbuliidae, as reported on by Yonge, of any trace of pallial food-collecting with the passage forward of a mucous string. In Cavolinia and Creseis the whole of the food-collecting is done by the 'Wimperfeld' of the wings and by the side lobes and median lobe of the foot. In Cymbulia the ciliary action of the 'Wimperfeld' is lost, and the emphasis is on feeding by the foot. Food particles travel to the mouth along two obliquely transverse grooves, bounded in front by the two lateral lobes, forming raised margins, and behind by the unpaired median lobe. The mouth is 
depressed into a funnel into which these ciliary currents lead downwards. The ciliary tracts on the wings are much reduced and there is little if any collection of food; the flapping of the wing dislodges alighted particles. In Gleba there is the same situation in essentials, but the parts of the foot are here drawn out into a long, spatuliform 'proboscis', lying parallel to the surface of the wings, with the mouth in a central cleft near the tip. Ciliated grooves carrying food particles proceed along the rounded edges of the 'proboscis', the lateral lobes of the foot forming the upper margin and the highly modified median lobe the lower.

A glance at Pelseneer's figures for Cavolinia and Cymbulia shows why pallial food-collecting cannot take place in these forms, at least by a food string emerging anteriorly to the head in the method used by Limacina. In these higher pteropods the visceral mass has turned through $180^{\circ}$ to bring the anus to the left side of the mantle cavity of the now bilaterally symmetrical body. The position of the mantle cavity is now ventral, and its opening is separated from the mouth by the interposition of the foot and wings. In the floating and swimming position, especially in Cymbulia, which lies on its dorsal surface with the ventral mouth and foot uppermost, this change in orientation of the mantle cavity may be explained by reference to the requirements of the animal in flotation.

A food string from the mantle cavity would thus be unable to pass to the mouth in the same way as in Limacina, and it is difficult to visualize how Cavolinia or Cymbulia might make use of the mantle in feeding. But the problem remains of the relatively huge pallial gland developed in cavoliniids and cymbuliids just as in limacinids. In the latter its function is evidently wholly concerned with feeding, and its survival in the higher families is puzzling to explain in the absence of a mucous feeding role. From the histology of the pallial gland and from the evidence of simplification of the pallial complex, this gland is almost certainly not a direct survival of the hypobranchial gland of prosobranchs which is a different structure that was lost with the gill. The function of the hypobranchial gland-detritus removal and sanitation of the pallial cavity-is scarcely in the least likely to be important in a pelagic mollusc in clear water. Further, the histology of the pallial gland is identical in all the Thecosomata, and we are clearly dealing with the same structure in each of the three families. While the issue of a mucous string from the pallial cavity in Cavoliniidae is feasible, with a changed course along the foot, it is not easily possible in Cymbuliidae which have a wide spread of the wings almost entirely closing off the opening of the pallial cavity. It may yet be worth further investigation of these pteropods to see if the pallial cavity and its gland actually play any role in collecting food.

Whatever the role of the pallial cavity in the Cymbuliidae, the ciliary collecting fields on the wings are greatly reduced, and in Gleba they appear to be quite lost. In the Cavoliniidae, where they are probably best developed, 
they are even here of much less importance than the lobes of the foot. In the Limacinidae they seem to be of minimal importance in feeding; more than any other family this group retains the use of the widely expanded median lobe or 'sole' of the foot.

Of other evolutionary trends connected with feeding in Thecosomata, we may mention the reduction of the buccal mass. The Cavoliniidae have this structure moderately well developed, with salivary glands, jaws and radula. The same is true of the less advanced Limacinidae. In Cymbulia, Yonge states that the buccal mass is 'much less developed than in the two species already described', and in Gleba there is 'no buccal mass, hence no jaws, radula or salivary glands'. It is lacking also in Corolla.

The essential structure of the stomach and gizzard is fairly constant in all these groups. The gizzard was regarded by Yonge as probably another structure 'handed down from carnivorous ancestors and clearly of little use to an animal which feeds by ciliary mechanisms'. In Limacina, however, the gizzard has only to be seen in action to realize its usefulness, both as a diatom mill and, by the action of its muscular wall, as a pumping device, regulating the inflow and outflow from the digestive diverticulum. The important part played by muscle, even in a ciliary feeder, is well emphasized in a creature small enough to view with its working stomach intact, and, as stressed by Yonge (I949) in connexion with the eulamellibranch Tellinacea, we should not undervalue the role of muscle in the digestive economy of ciliary feeders. Comparison may be made with Scaphander which uses its gizzard to crush the shells of small bivalves, and here differs only in its size and choice of food from Limacina.

The tiny style sac of Limacina, though of much smaller size, corresponds exactly to that described by Yonge in Creseis and by Howells (1936) in Cymbulia, and said by Meisenheimer (1905) to be retained in all Thecosomata. Here it can be little more than a vestige, as it is impossible to see of what use a style could be in its normal role of stirring and moving the stomach contents. Moreover, an amylolytic enzyme has never been demonstrated in Thecosomata, and from the nature of the food is likely to be little needed. The survival of the style sac in this group once again impresses us with the great unity in the pattern of the stomach shown among so many of the mollusca.

\section{SUMMARY}

The biology of the thecosomatous pteropod, Limacina retroversa, is discussed with special reference to the swimming mechanism, mode of food collection and structure and action of the alimentary canal. The ciliary currents of the foot and pallial cavity are described in detail, in relation to the collection of food particles, and it is shown that the pallial cavity, with its mucus-secreting pallial gland, plays the principal role in gathering food from the surrounding water. A mucous food string is compacted and carried forward to the mouth. 
The structure of the gizzard and the stomach is described, and the toothed, muscular gizzard is shown to form a mechanism for crushing diatom frustules. The vestigial style sac, and the epithelium of the digestive diverticulum are described and compared with those of other Thecosomata.

\section{REFERENCES}

Hoffmann, H., 1939. Opisthobranchia, in Bronn's Klassen und Ordnungen des Tierreichs. Mollusca, II, Vol. 3.

Howells, H. H., I936. The anatomy and histology of the gut of Cymbulia peronit (Blainville). Proc. malacol. Soc. Lond., Vol. 22, pp. 62-72.

HsiaO, S. C. T., 1939. The reproductive system and spermatogenesis of Limacina (Spiratella) retroversa. Biol. Bull., Wood's Hole, Vol. 76, pp. 7-25.

Lebour, MARIE V., I918. The microplankton of Plymouth Sound from the area beyond the breakwater. F. Mar. biol. Ass. U.K., Vol. II, pp. I32-82.

_ I93I. Clione limacina in Plymouth waters. F. Mar. biol. Ass. U.K., Vol. I7, pp. $785-95$.

— 1932. Limacina retroversa in Plymouth waters. F. Mar. biol. Ass. U.K., Vol. I8, pp. 123-9.

Massy, ANNe L., I9I7. The gymnosomatous pteropods of the coasts of Ireland. Sci. Proc. R. Dublin Soc., Vol. 15, pp. 223-44.

Meisenheimer, J., 1905. Pteropoda. Wiss. Ergebn. 'Valdivia', Bd. 9.

Morton, J. E., I954. The Pelagic Mollusca of the Benguela Current. Pt. I. With an account of the reproductive system and sexual succession of Limacina bulimoides. 'Discovery' Rep. (In the Press).

Pelseneer, P., I887. Report on the Pteropoda collected by H.M.S. Challenger. I. The Gymnosomata. Sci. Rep. 'Challenger', Zoology, Vol. I9.

— I888. Report on the Pteropoda collected by H.M.S. Challenger. II. The Thecosomata.... III. Anatomy. Sci. Rep. 'Challenger', Zoology, Vol. 23.

RUSSELL, F. S., I936. Observations on the distribution of plankton indicators in the mouth of the English Channel. F. Mar. biol. Ass. U.K., Vol. 20, pp. 507-22.

Stubbings, H. G., I937. Pteropoda. Sci. Rep. Murray Exped., Vol. 5, pp. 15-33.

Tesch, J. J., I946. The Thecosomatous Pteropods. I. The Atlantic. Dana Rep., Vol. 28.

- I948. The Thecosomatous Pteropods. II. The Indo-Pacific. Dana Rep., Vol. 30.

Thiele, J., I93I. Handbuch der systematischen Weichtierkunde. I. Jena.

YoNGE, C. M., I926. Ciliary feeding mechanisms in the thecosomatous pteropods. f. Linn. Soc. (Zool.), Vol. 36, pp. 417-29.

I949. On the structure and adaptations of the Tellinacea: deposit-feeding Eulamellibranchia. Phil. Trans. B, Vol. 234, p. 29. 